\section{9 \\ (a) \\ ATMÓSFERA \\ Opinion}

DOI: https://doi.org/10.20937/ATM.52907 $\underbrace{\text { NOAS DE }}_{\text {UNAM }}$

\title{
Can trees pollute cities?
}

\section{Zhi-Hua Wang}

School of Sustainable Engineering and the Built Environment, Arizona State University, Tempe, USA,

Today, humanity is everywhere witnessing environmental changes at unprecedented rate and scale, with anthropogenic activities (fossil fuel burning, landscape modification, socioeconomic development, etc.) as the primary contributors. As hotspots of concentrated population and human activities, cities encapsulate two key drivers of global changes, viz. the population growth and climate changes. As a result, cities, especially urban centers, are facing unique environmental challenges.

One prominent example is the phenomenon that urban cores are warmer than their rural surroundings, known as the urban heat island (UHI) (Oke, 1973). This well-known UHI effect is, however, rarely a singular or stand-alone issue, but closely entangled with other urban challenges such as degraded environmental quality (air, noise, and light pollution), loss of ecosystem diversity, stress of resource demand, and vulnerability of infrastructure.

The U.S.-Mexico border region provides an example area of the sustainability challenges faced by cities. The region faces the "double exposure" to climatic and globalization processes (Wilder et al., 2010), where rapid urbanization and socioeconomic development render the region susceptible to elevated temperature, air pollution, and water scarcity. In past decades, research effort has been devoted to study the UHI effect in this region (e.g. Garcia-Cueto et al., 2007; Villanueva-Solis, 2017), but interactions among the UHI, air quality, and other anthropogenic-induced environmental challenges are largely under-explored. 
The nocturnal UHI effect is pronounced in Mexico City (Jauregui, 1997), on top of which severe air pollution episodes (Fig. 1) and extreme heat waves can concomitantly develop under "blocking high" pressure synoptic systems (Charney and DeVore, 1979).
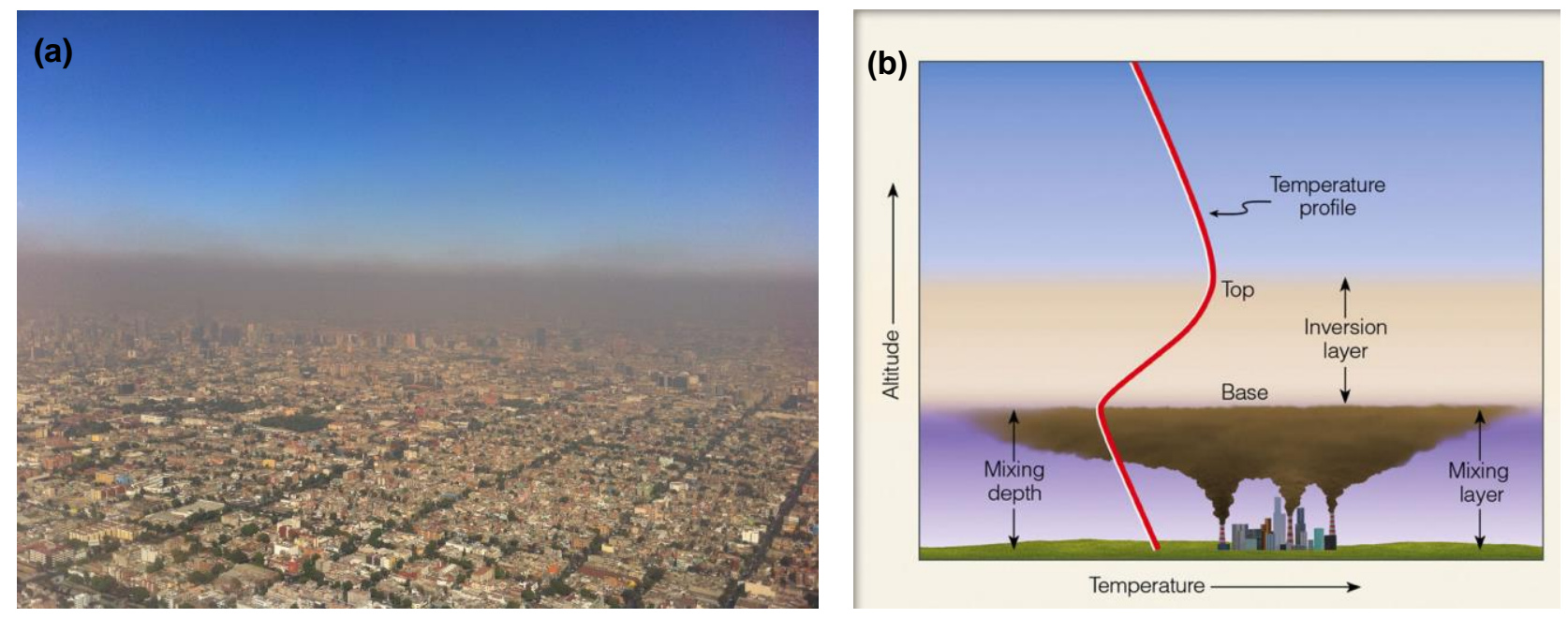

Figure 1. (a) Air pollution over the Mexico City (Source: Wikipedia. Photo created by Fidel Gonzalez). (b)

Schematic of pollution dispersion in the urban boundary layer. The bold red line shows the temperature profile with elevation with the slope indicating the lapse rate.

Across the U.S.-Mexico border and beyond, urban greening, especially the use of urban trees, has emerged as an effective means for mitigating and adapting to urban environmental challenges (Wang et al., 2016). The primary benefits of urban trees include the cooling (evapotranspiration and shading) effect, stormwater buffering, reduction of air, noise and light pollution, and improving human health. Nevertheless, recent studies have reported that unintended consequences can arise and that trees can potentially "pollute" the urban environment. The problem come from two different aspects: (1) on the passive side, careless planting of urban trees can lead to trapping of pollutants emitted in the urban canopy layer, especially in densely populated areas (e.g. Vos et al., 2013); or (2) trees can emit large 
amount of volatile organic compounds (VOCs) that react to form ozone, thus become an active source of pollution especially under elevated temperature (e.g. Churkina et al., 2017); an issue particularly challenging for cities in hot climate zones (e.g. Mexico City or Phoenix metropolitan). In what follows, we aim to discuss the mechanisms, plant physiology, and the spatio-temporal patterns of these phenomena in a broader context, and hopefully to provide some clues to interpret and demystify the fact that trees can potentially contribute to air pollution in cities.

As "passive" (non-organic) elements in the built environment, occasions do arise where trees can trap pollutants in the street canyon temporally, especially if the presence of trees disturbs the wake interference flow and generates isolated vortices in the street canyon. Figure 2 shows some sample results of pollutant concentration using numerical simulations of computational fluid dynamics (Wang et al., 2018). It is noteworthy that high concentration of vehicle-emitted air pollutants can be accumulated at the lower corner around the windward wall due to the presence of tall trees ("TreeTall" case) in the middle of the street canyon. 

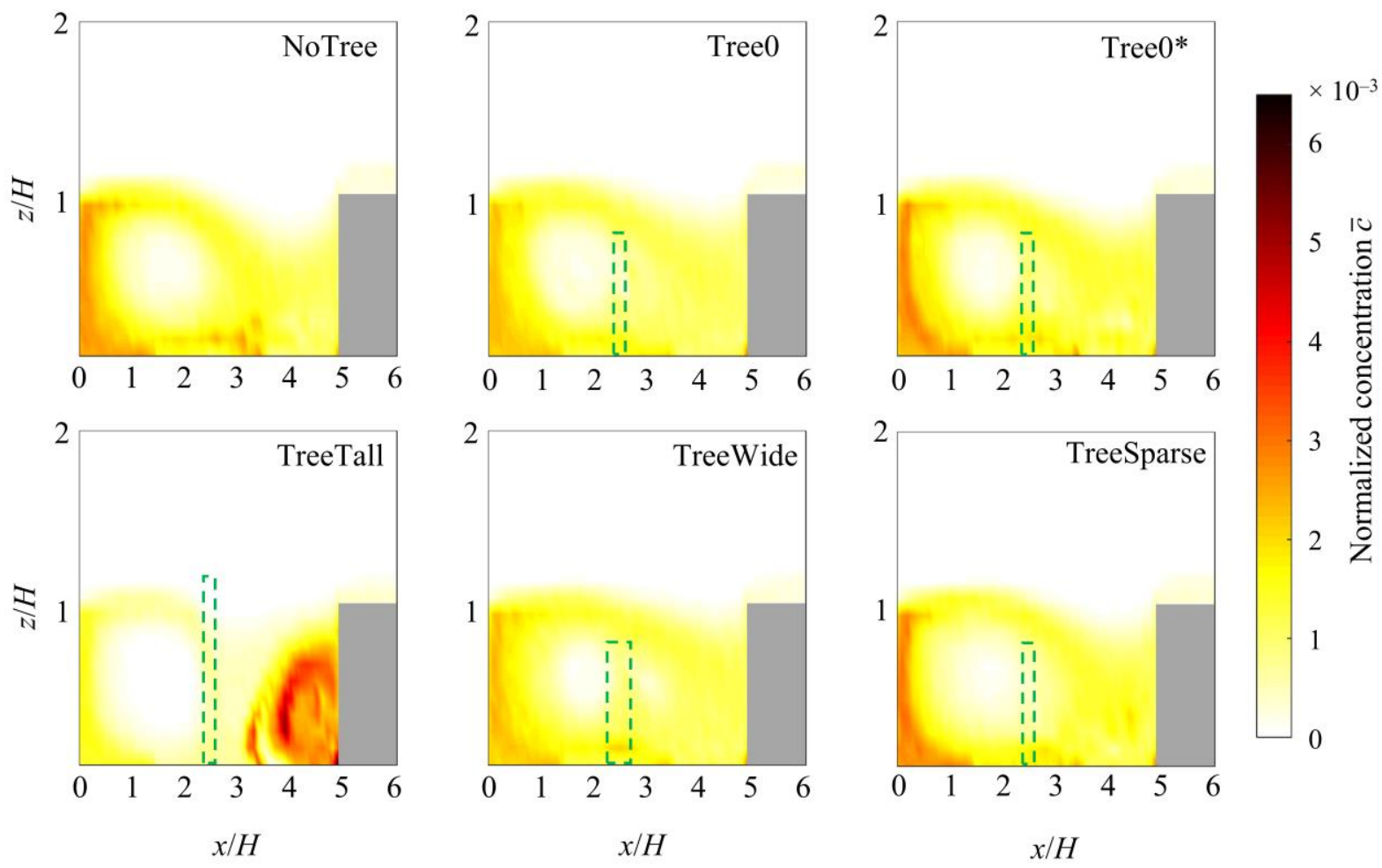

Figure 2. Results of normalized concentrations in a broad street canyon with building-height-to-canyon-width ratio $(H / W)=0.2$ for different arrangement and morphology of urban trees. The prevailing wind flows from left to right. The green boxes mark the positions of modeled tree canopies. (From Wang et al. 2018)

The cooling effect of trees can, in addition, reduce the height of the atmospheric boundary layer (ABL) over built terrains (Song and Wang, 2016), hence increase the average concentration of pollutants in the ABL (Wu et al., 2019). This latter impact of trees on pollution distribution over the entire urban boundary layer (rather than within the street canyon) has been, hitherto, largely under-explored and can shed much light on future studies of the coupled UHI-air quality via urban land-atmosphere interactions.

In addition to the passive modification of urban flow patterns and the boundary layer structure by their very presence, urban trees are organic elements and play active plant physiological functions, albeit under elevated thermal and atmospheric stresses in the built environment (Calfapietra et al., 2015). To unravel the active and participatory roles played by urban trees in regulating air quality, it is necessary to 
account for the interactions between plant physiology and the thermal and atmospheric environments in cities (UHI included). The primary factors include, but are not limited to, emissions and adsorption of VOCs through stomatal openings, collection and deposition of solid pollutants (e.g. particulate matter or $\mathrm{PM}$ ) on leaf surfaces, biogenic changes of urban atmospheric status (ambient temperature, gas composition, ABL height, etc.).

Let us first consider ozone as a gaseous pollutant. In general, ozone concentration is found to increase with ambient temperature (Camalier et al., 2007), such that ozone exceedance is often found in cities located in tropical regions (e.g. Mexico City, Sao Paulo, etc.), or in moderate regions during heatwave events (Wu et al., 2019). On one hand, urban trees contribute to the elevated ozone concentration via enhanced isoprene emissions under higher temperatures, hence appear as a biogenic source of pollution as found by Churkina et al (2017). On the other hand, the opposite effect emerges since trees can directly remove ozone through deposition (Sicard et al., 2018) and/or indirectly lead to lower ozone concentration by its "secondary" effect of cooling the built environment (Fallmann et al., 2016; Wang et al., 2019).

We digress here to elaborate a little more on the secondary effect of trees as a means of heat mitigation (viz. their active cooling effect via evapotranspiration, in contrast to their passive cooling by shading), which, as a matter of fact, has been the primary concern of using urban trees (and urban forestry) by planners and policy makers in many cities. Figure 3 shows the digital and thermal images of urban trees taken in a residential neighborhood in Arizona, where the tree crown and leaves are cooler than the built areas. 

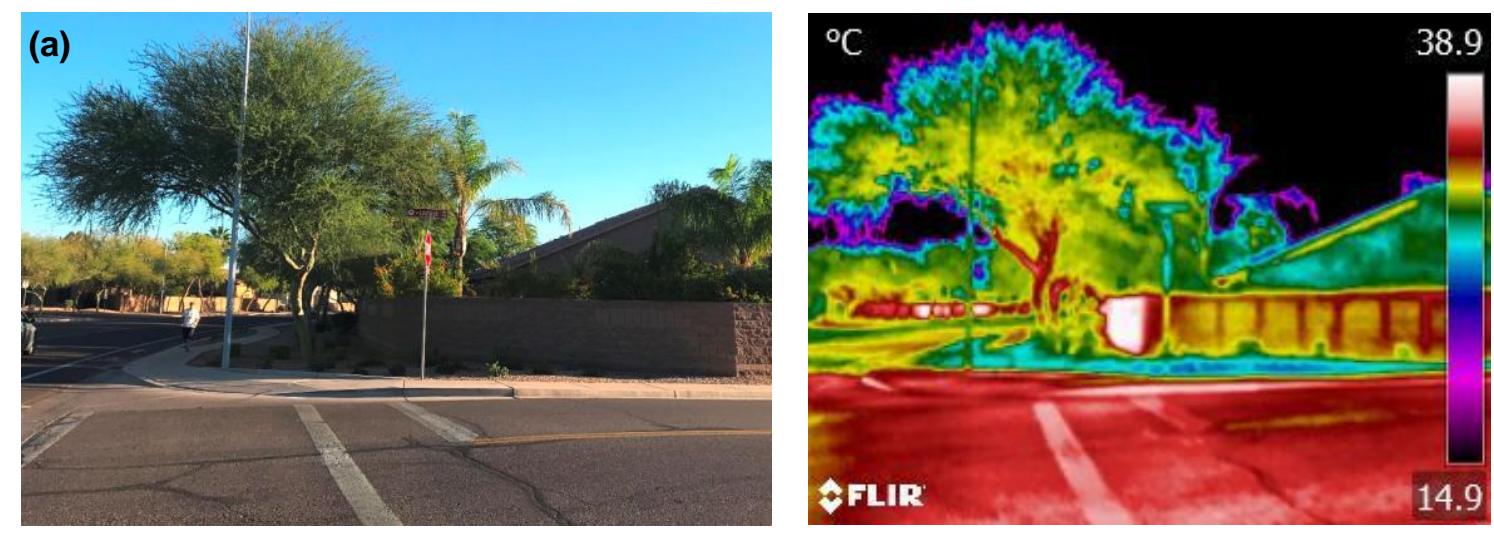

Figure 3. Comparison of (a) digital and (b) thermal images of urban trees in a residential neighborhood of Chandler, AZ. The thermal image was taken at 8:30pm LST, 06/10/2017, using FLIR T400 infrared camera. (Photos created by the Author)

Nevertheless, here we want to illustrate an intriguing phenomenon that pedestrians may sometimes find themselves being surrounded by warmer air when walking underneath trees. This local "warming" effect is transitory and typically occurs during summer evenings in cities of arid or semi-arid regions (such as desert cities in U.S.-Mexico border region). The effect can be seen from the thermal image in Fig. 3b where the skin temperature tree trunk is as hot as the asphalt road. While further investigation to the cause of the warming effect is pending, we suspect that it is likely due to the lack of transpiration in the trunk (unlike leaves), combined with the effect of local mixing and trapping of heat arising from adjacent pavement.

Despite being local and transitory, the warming effect could potentially lead to the exacerbation of air quality in the neighborhood for pollutants whose concentrations are positively correlated with temperature (e.g. ozone). This example shows why the use of urban trees, being 3D and organic, for improving thermal environment and air quality in cities is much more complex than, say artificial (inorganic) shade or turf for cooling, or even other green infrastructure (e.g. green roofs and lawns) with planar (2D) layout. 
Back to the impact of urban trees on air quality, the transport and fate of other pollutants, be it gaseous, like ozone, or solid particulates, do not generally bear simple monotonic (let alone "linear", as preferred by many) correlation with the presence of trees and their physiology. To depict the spatiotemporal patterns of how urban trees affect the concentration of an individual type of pollutant, much detailed analysis needs to be carried out to establish the interlink with a long list of attributes, including the species of pollutant, photochemical reactions, modification of flow physics, ambient temperature, atmospheric and soil status, stomatal resistance, water stress, and so on. To further complicate the problem at hand, often these factors linking the presence of urban trees and their final effect on air quality operate simultaneously with competing mechanisms. Considering the temperature dependency for example, the formation of ammonium nitrate favors a cooler environment, whereas the emissions of precursors to secondary organic aerosols increase with temperature.

The impact of urban trees on PM is particularly critical for cities in developing countries (e.g. Mexico) where streets are often found unpaved in the outskirt of cities, or in semiarid/desert environments (e.g. Southwest U.S.) where exposed bare soils or dry riverbeds are constant sources of dust storms (haboobs). A recent case study in the Basque Country (de Jalon et al., 2019) found that urban trees, most noticeably coniferous forests, can effectively remove both PM and ozone by dry deposition, with roughly equal efficacy. The use of coniferous trees, especially native species, is even more fitful for cities in semiarid and arid environment facing the "double evil" of excessive heat and water scarcity. 


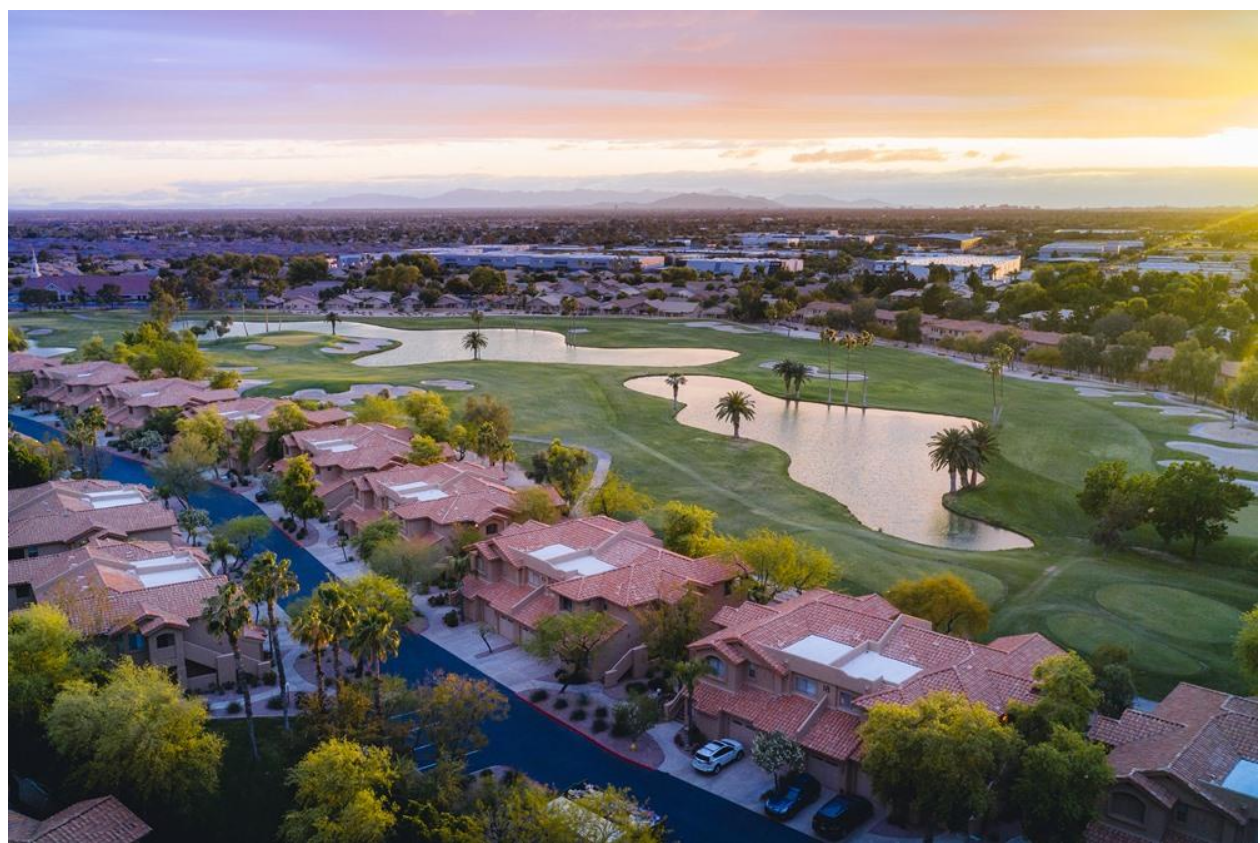

Phoenix, Arizona. Photo: Peiyuan Li

The current research endeavor is at its very infancy to further improve our fundamental understanding of the impact of trees on urban air quality. Tremendous effort needs to be devoted to this field before we can answer the question raised in the title, viz. under what circumstances we will see trees "pollute" our cities, and how to avoid this unfavorable and unintended consequence? At the current stage, it is reasonable for us to speculate that mixed results will arise from various studies aiming to tackle the problem from different angles. Nevertheless, accounting for the trade-offs of multifaceted effects and their magnitudes, we are generally optimistic to the perspective that the overall (or "net") effect of urban trees will be beneficial to improve the total environmental quality of cities under some holistic sustainability or liveability measures. 
Yet, we do learn something unequivocal from the existing studies as general guidelines to foster more favorable outcomes of using urban trees as sustainable urban planning strategies. Some key guidelines include (i) the selection of tree species (preferably native, drought-tolerant, resistant to pests and diseases, and non-allergenic), (ii) careful management of trees (spatial arrangement of plantation, scheduled irrigation, fertilization, and maintenance, etc.), and (iii) combined use of trees and other complementary urban development strategies (e.g. lawns, eco-roofs, cool pavement materials, etc.) to achieve the optimum environmental co-benefits. 


\section{References}

Calfapietra, C., J. Penuelas, and U. Niinemets (2015), Urban plant physiology: adaptation-mitigation strategies under permanent stress, Trends in Plant Science, 20(2), 72-75. doi: 10.1016/j.tplants.2014.11.001.

Camalier, L., W. Cox, and P. Dolwick (2007), The effects of meteorology on ozone in urban areas and their use in assessing ozone trends, Atmospheric Environment, 41(33), 7127-7137. doi: 10.1016/j.atmosenv.2007.04.061.

Charney, J. G., and J. G. Devore (1979), Multiple flow equilibria in the atmosphere and blocking, Journal of the Atmospheric Sciences, 36(7), 1205-1216. doi: 10.1175/15200469(1979)036<1205:mfeita>2.0.co;2.

Churkina, G., F. Kuik, B. Bonn, A. Lauer, R. Grote, K. Tomiak, and T. M. Butler (2017), Effect of VOC emissions from vegetation on air quality in Berlin during a heatwave, Environmental Science \& Technology, 51(11), 6120-6130. doi: 10.1021/acs.est.6b06514.

de Jalon, S. G., P. J. Burgess, J. C. Yuste, G. Moreno, A. Graves, J. H. N. Palma, J. Crous-Duran, S. Kay, and A. Chiabai (2019), Dry deposition of air pollutants on trees at regional scale: A case study in the Basque Country, Agricultural and Forest Meteorology, 278, 10, doi: 10.1016/j.agrformet.2019.107648.

Fallmann, J., R. Forkel, and S. Emeis (2016), Secondary effects of urban heat island mitigation measures on air quality, Atmospheric Environment, 125, 199-211. doi: 10.1016/j.atmosenv.2015.10.094.

Garcia-Cueto, O. R., E. Jauregui-Ostos, D. Toudert, and A. Tejeda-Martinez (2007), Detection of the urban heat island in Mexicali, B. C., México and its relationship with land use, Atmósfera, 20(2), 111-131. 
Jauregui, E. (1997), Heat island development in Mexico City, Atmospheric Environment, 31(22), 38213831, doi: 10.1016/s1352-2310(97)00136-2.

Oke, T. R. (1973), City size and the urban heat island, Atmospheric Environment, 7, 769-779.

Sicard, P., E. Agathokleous, V. Araminiene, E. Carrari, Y. Hoshika, A. De Marco, and E. Paoletti (2018), Should we see urban trees as effective solutions to reduce increasing ozone levels in cities?, Environmental Pollution, 243, 163-176. doi: 10.1016/j.envpol.2018.08.049.

Song, J., and Z. H. Wang (2016), Diurnal changes in urban boundary layer environment induced by urban greening, Environmental Research Letters, 11, 114018. doi: 10.1088/1748$9326 / 11 / 11 / 114018$.

Villanueva-Solis, J. (2017), Urban Heat Island Mitigation and Urban Planning: The Case of the Mexicali, B. C. Mexico, American Journal of Climate Change 6(1), 22-39. doi: 10.4236/ajcc.2017.61002.

Vos, P. E. J., B. Maiheu, J. Vankerkom, and S. Janssen (2013), Improving local air quality in cities: To tree or not to tree?, Environmental Pollution, 183, 113-122. doi: 10.1016/j.envpol.2012.10.021.

Wang, C., Q. Li, and Z. H. Wang (2018), Quantifying the impact of urban trees on passive pollutant dispersion using a coupled large-eddy simulation-Lagrangian stochastic model, Building and Environment, 145, 33-49. doi: 10.1016/j.buildenv.2018.09.014.

Wang, C., Z. H. Wang, C. Wang, and S. W. Myint (2019), Environmental cooling provided by urban trees under extreme heat and cold waves, Remote Sensing of Environment, 227, 28-43. doi: 10.1016/j.rse.2019.03.024. 
Wang, Z. H., X. Zhao, J. Yang, and J. Song (2016), Cooling and energy saving potentials of shade trees and urban lawns in a desert city, Applied Energy, 161(3), 437-444, doi: 10.1016/j.apenergy.2015.10.047.

Wilder, M., C. A. Scott, N. P. Pablos, R. G. Varady, G. M. Garfin, and J. McEvoy (2010), Adapting across boundaries: Climate change, social learning, and resilience in the U.S.-Mexico border region, Annals of the Association of American Geographers, 100(4), 917-928. doi: $10.1080 / 00045608.2010 .500235$.

Wu, Y. H., K. H. Zhao, J. P. Huang, M. Arend, B. Gross, and F. Moshary (2019), Observation of heat wave effects on the urban air quality and PBL in New York City area, Atmospheric Environment, 218, 17024. doi: 10.1016/j.atmosenv.2019.117024. 